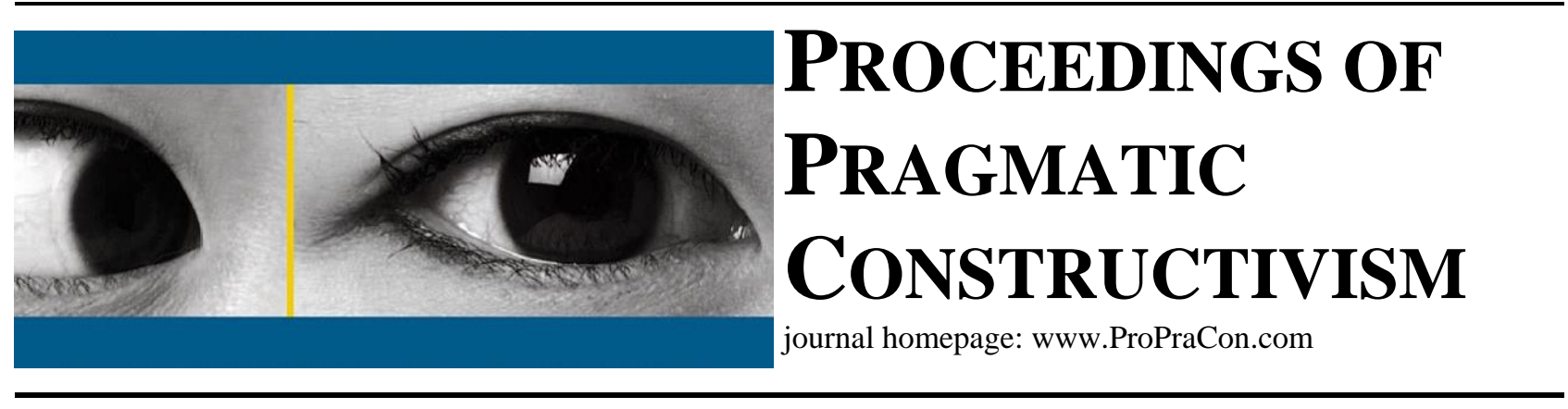

\title{
Methodologies for using performance measurement
}

\author{
Lino Cinquini \\ Professor of Management Accounting \\ Scuola Superiore Sant'Anna \\ Piazza Martiri della Libertà 33, 56127 Pisa, Italy; l.cinquini@sssup.it \\ Falconer Mitchell \\ Professor of Management Accounting \\ University of Edinburgh Business School \\ 29 Buccleuch Place, Edinburgh EH8 9JS, UK; f.mitchell@ed.ac.uk \\ Hanne Nørreklit \\ Professor of Management Control \\ Aarhus University; School of Business and Social Sciences; Department of Economics and Business \\ Fuglesangs Allé 4, 8210 Aarhus V, Denmark; $\underline{\text { hann@asb.dk }}$ \\ Andrea Tenucci \\ Assistant Professor \\ Scuola Superiore Sant'Anna \\ Piazza Martiri della Libertà 33, 56127 Pisa, Italy; a.tenucci@sssup.it
}

\begin{abstract}
The speech explores the operational dynamics of a PMS at the interface between a parent company and its subsidiary. The research is based on two case studies. The companies are both subsidiaries of US multinational companies located in Italy. Both are market leaders of different sectors and governed by different strategic mentalities and managerial methodologies that reflect the specific business strategy adopted by the parent company. The methodologies of performance management in use by the two companies are addressed respectively as pragmatic constructivism and precategorized analytical data paradigm.

Drawing on the narrative of the two cases we conclude that these two methodologies of performance management use support two alternative views of strategy: competitive advantage and resource-based view. The findings show that it is not simply the structure or technical design of a PMS that will determine its impact on an organization and ultimately its practical success but also the strategic mentality that underpins its functional rationale.
\end{abstract}




\section{METHODOLOGIES FOR USING PERFORMANCE MEASUREMENT}

Lino Cinquini, Scuola Superiore Sant'Anna, Pisa, Italy.

Falconer Mitchell, University of Edinburgh, Edinburgh, UK.

Hanne Nørreklit, Aarhus University, Aarhus, Denmark.

Andrea Tenucci, Scuola Superiore Sant 'Anna, Pisa, Italy.

Götheborg - October, 27th-28th 2011

\section{Lefmo \\ EQUIS}

\section{AARHUS

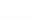 \\ Background}

> Two Italian subsidiaries of two multinational US companies

> More or less same financial and non financial measures

> Design, use and perceptions of measures very different

> Different performance measurement methodologies?

> Research on performance measurement systems

> Techniques

> Adoption, diffusion, success

> Use

> Research gap on practice methodology 

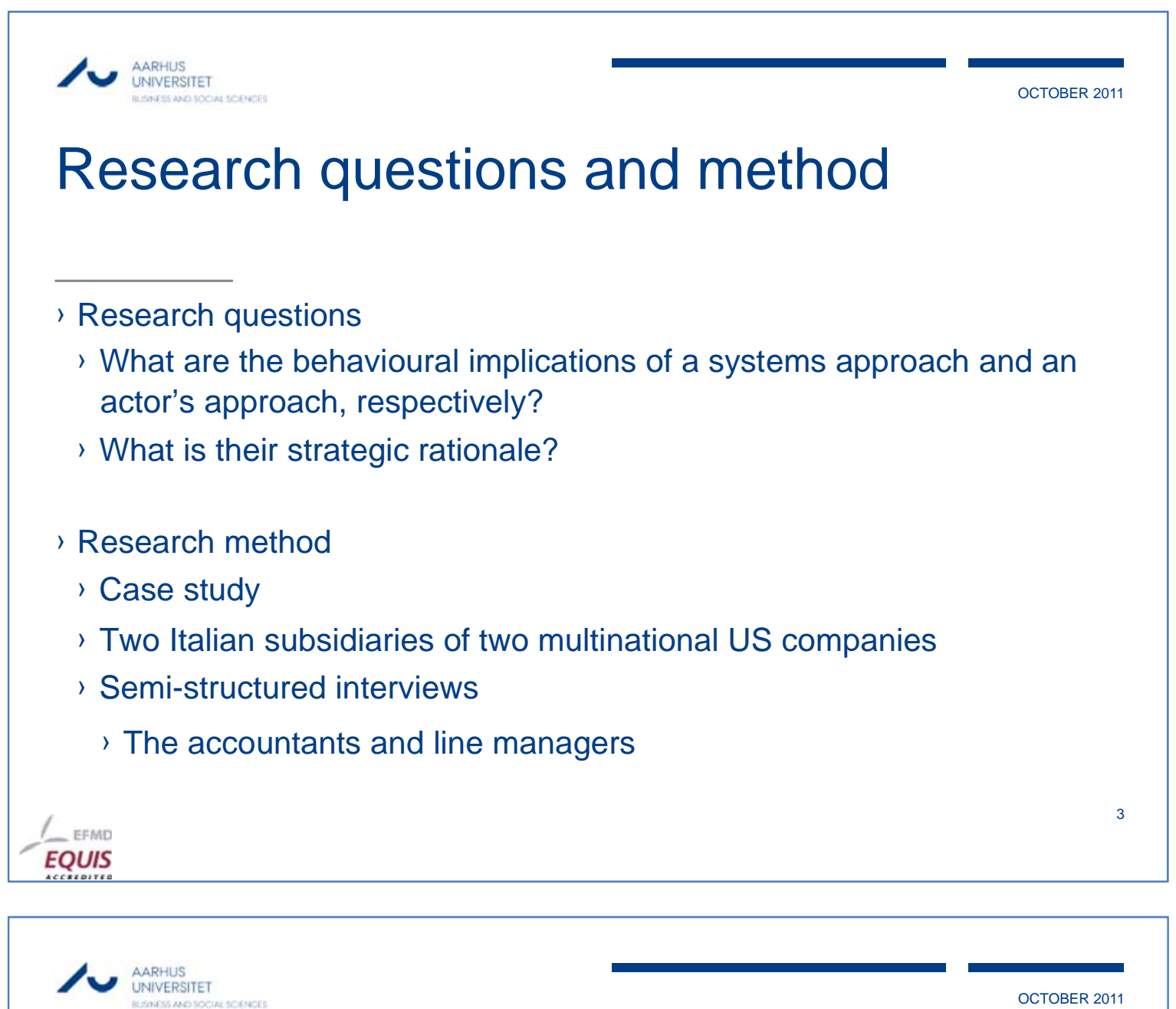

\section{Performance measurement approaches}

\section{> Systems approach}

$>$ Assumptions

> Objectivism: Physical and social are the same

> Adapt to the environment - stimulus response

> Observations of facts

> Management of PM

> Fit with the environment

> Hierarchical design and deployment

> Employees adapt to norm

> Mechanical reaction

> Direct
> Actor's approach

> Assumptions

> The actor constructs himself in relation to the environment

> Facts, possibilities, values and communication

> Understanding

> Management of PM

> Phenomenological grounding

> Interactive design and deployment

> Understanding and values

> Intrinsic motivation

> Dialogue 


\section{Case A: Background and strategy}

> Founded in 1956 but acquired in 2002 by US company

> Manufacturing industry - compressors, turbines and generators

> Until the acquisition R\&D oriented, but after very finance oriented

> "... The parent company of today is not a product-driven company, but more a finance driven company. The company buys companies in the market, merges them and maybe the following year they are sold on to another company...." (Finance Manager)

> Centralised decision making

> Increased growth, standard quality and efficiency

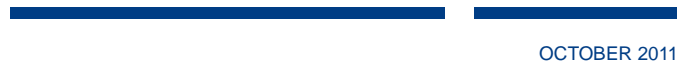

\section{Case A: Performance measurement}

> Targets determined by the parent company

> Hierarchical top-down deployment

> Tight and mechanical performance evaluation

> Ranking of employee performance - rewards linked to ranking

> Top $10 \%$ are the "top talent" and they get higher salary rates

> 20\% are "high performers", $60 \%$ are average

> The worse $10 \%$ are the "least efficient"

> Systems approach 

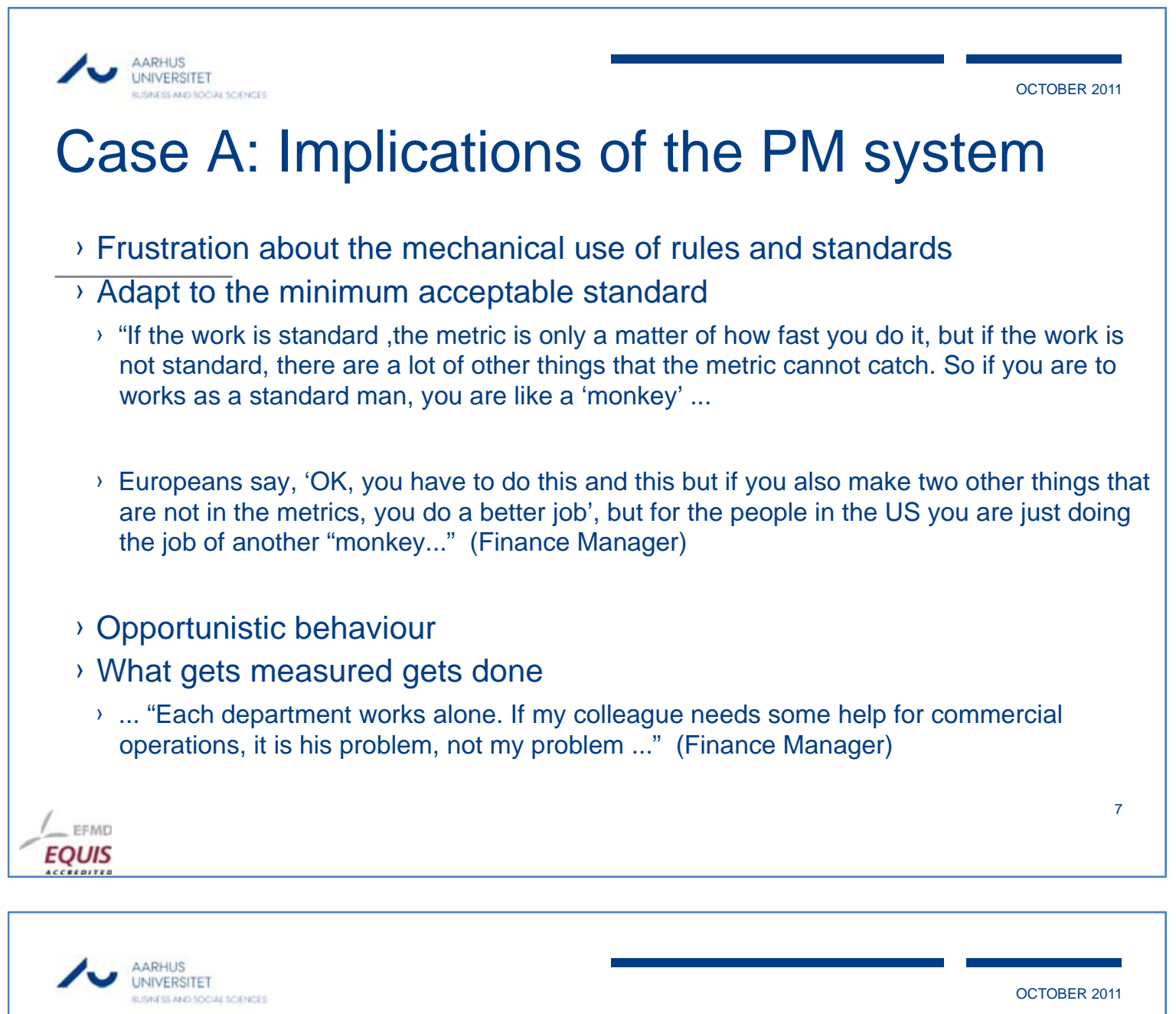

OCTOBER 2011

\section{Case B: Background and strategy}

, Founded: parent company in 1976; Italian subsidiary in 1987

> Software industry: business analytics software and services

> Subsidiary in Italy: sales, assistance and consulting

> Steady revenue growth and profitability

> R\&D oriented $-23 \%$ of revenues reinvested

> Long-term profitability more important than the short term

> Customers and employees are key resources:

> "... we are interested in building a long-term relationship with the customer because our sales policy is mainly new sales plus renewals; so it is very important to maintain this rule ..." and "... we try to do the best in order to maintain talent, to give people opportunities to grow in terms of operational skills ..." 

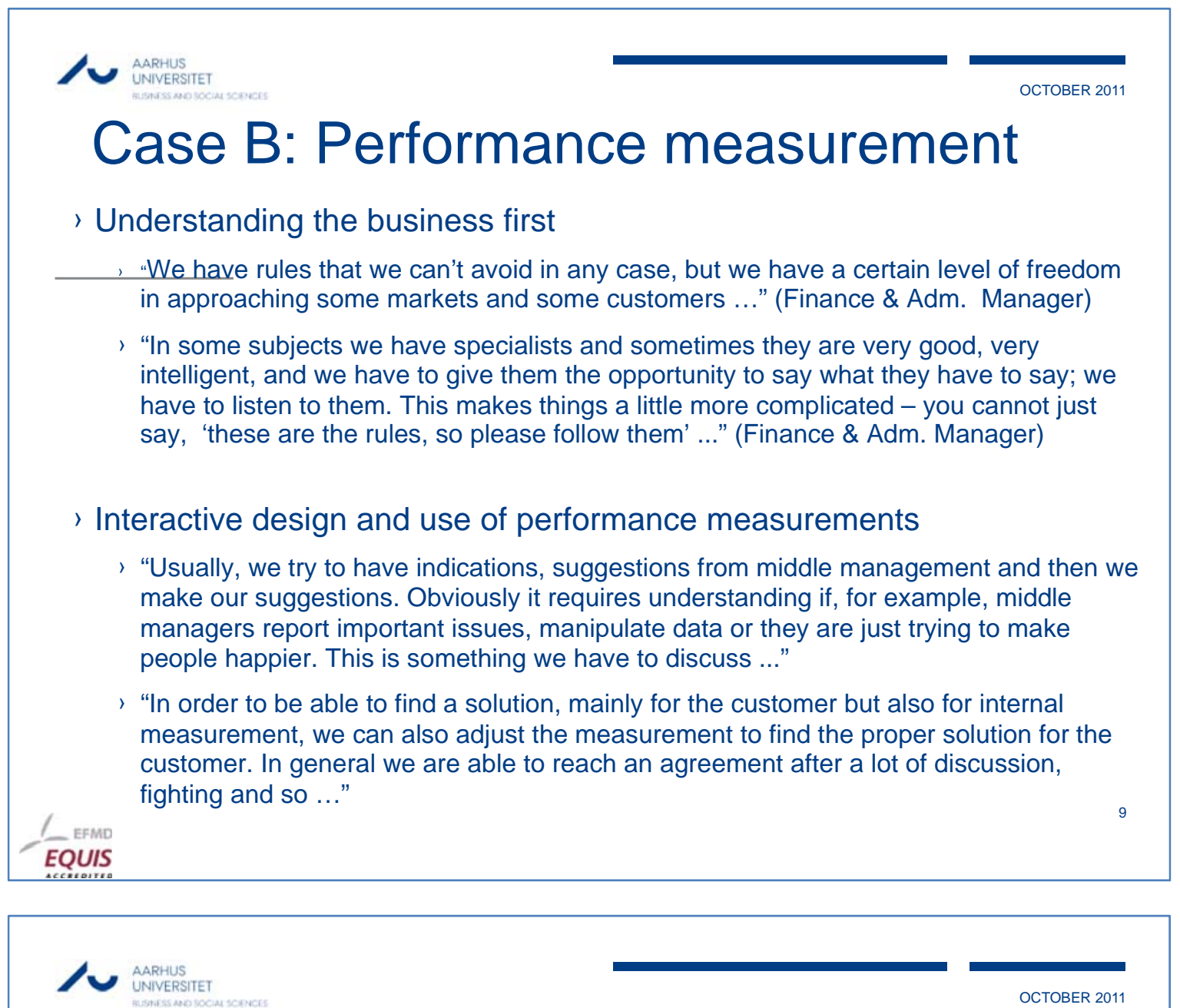

\section{Case B: Implications of the PM system}

\section{> The employees are perceived to be a resource for the company}

> "The most important thing is that the people don't feel that they are just a number. They need to think that they are important inside the organisation. For me this is the best way to motivate" (Business Developer)

> “... We are not paying people over the market, but we try to give them, in general, an opportunity to grow professionally. We don't always succeed - often, for example, it happens that a customer wants our people ..." (Finance \& Adm. Manager)

> The PM system has some appeal to extrinsic motivation of the employees

> "We introduced the first version of our bonus plan in 1996, and starting with sales people the reaction was very good because people felt they had an opportunity to earn money if their results were good. In general, they are more motivated to reach the goals. Obviously it is important to set achievable goals and targets because it can have a very bad impact if targets are unreasonable or too high" (Finance \& Adm. Manager) 


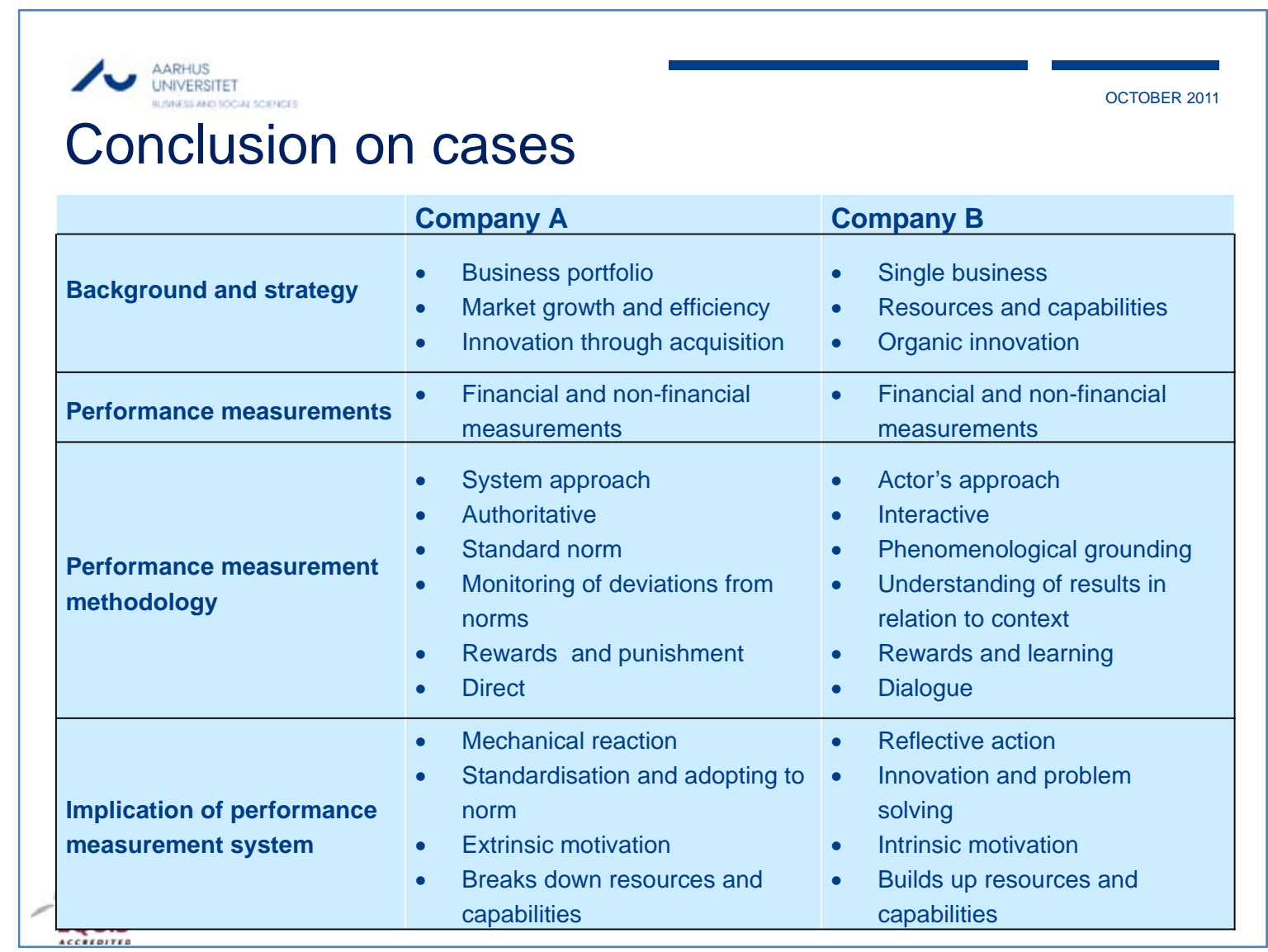

\section{Reflections on strategic rationale}

\section{Competitive vs. sustained competitive advantage}

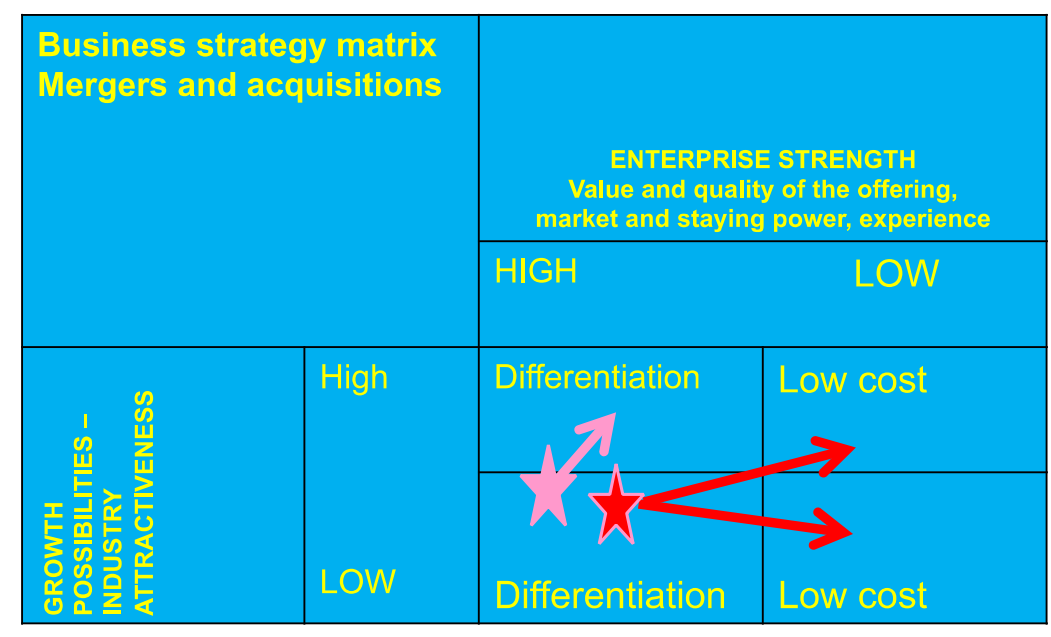

\begin{tabular}{|l|}
\hline - Standardise products \& process \\
- Increase sales \\
- Reduce cost \\
- Reduce R\&D \\
\hline
\end{tabular}

